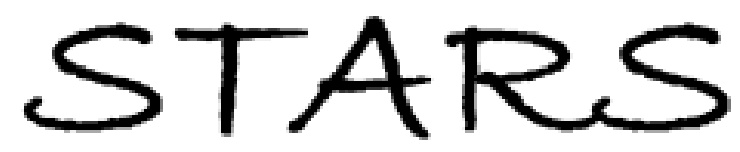

University of Central Florida

STARS

$1-1-2005$

\title{
Effect of ultraviolet radiation exposure on room-temperature hydrogen sensitivity of nanocrystalline doped tin oxide sensor incorporated into microelectromechanical systems device
}

\author{
Satyajit Shukla \\ University of Central Florida \\ Rajnikant Agrawal \\ University of Central Florida \\ Hyoung J. Cho \\ University of Central Florida \\ Sudipta Seal \\ University of Central Florida \\ Find similar works at: https://stars.library.ucf.edu/facultybib2000 \\ banversity bld exiftral Florida Libraries http://library.ucf.edu
}

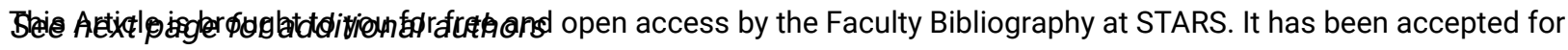
inclusion in Faculty Bibliography 2000s by an authorized administrator of STARS. For more information, please contact STARS@ucf.edu.

\section{Recommended Citation}

Shukla, Satyajit; Agrawal, Rajnikant; Cho, Hyoung J.; Seal, Sudipta; Ludwig, Lawrence; and Parish, Clyde, "Effect of ultraviolet radiation exposure on room-temperature hydrogen sensitivity of nanocrystalline doped tin oxide sensor incorporated into microelectromechanical systems device" (2005). Faculty Bibliography 2000s. 5664.

https://stars.library.ucf.edu/facultybib2000/5664

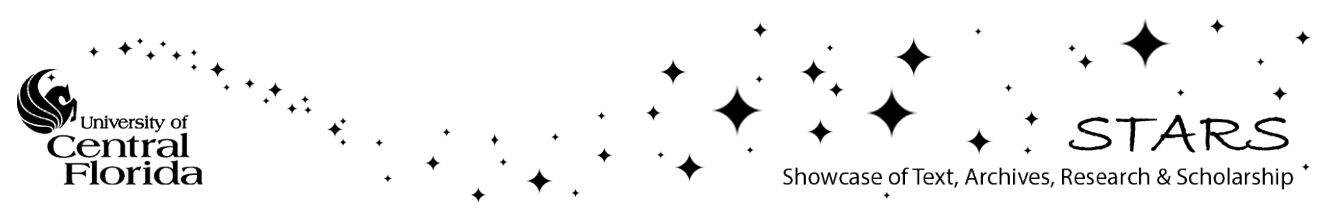




\section{Authors}

Satyajit Shukla, Rajnikant Agrawal, Hyoung J. Cho, Sudipta Seal, Lawrence Ludwig, and Clyde Parish 


\section{Effect of ultraviolet radiation exposure on room-temperature hydrogen sensitivity of nanocrystalline doped tin oxide sensor incorporated into microelectromechanical systems device}

Cite as: J. Appl. Phys. 97, 054307 (2005); https://doi.org/10.1063/1.1851597

Submitted: 04 October 2004 . Accepted: 03 December 2004 . Published Online: 15 February 2005

Satyajit Shukla, Rajnikant Agrawal, Hyoung J. Cho, Sudipta Seal, Lawrence Ludwig, and Clyde Parish

\section{ARTICLES YOU MAY BE INTERESTED IN}

Hydrogen-discriminating nanocrystalline doped-tin-oxide room-temperature microsensor Journal of Applied Physics 98, 104306 (2005); https://doi.org/10.1063/1.2132095

$\mathrm{In}_{2} \mathrm{O}_{3}$ nanowires as chemical sensors

Applied Physics Letters 82, 1613 (2003); https://doi.org/10.1063/1.1559438

Electrical, optical, and structural properties of indium-tin-oxide thin films for organic lightemitting devices

Journal of Applied Physics 86, 6451 (1999); https://doi.org/10.1063/1.371708






\title{
Effect of ultraviolet radiation exposure on room-temperature hydrogen sensitivity of nanocrystalline doped tin oxide sensor incorporated into microelectromechanical systems device
}

\author{
Satyajit Shukla, ${ }^{a)}$ Rajnikant Agrawal, Hyoung J. Cho, and Sudipta Seal ${ }^{\text {) }}$ \\ Advanced Materials Processing and Analysis Center (AMPAC) and Mechanical Materials Aerospace \\ Engineering (MMAE) Department, Engineering 381, University of Central Florida, 4000 Central Florida \\ Boulevard, Orlando, Florida 32816 \\ Lawrence Ludwig and Clyde Parish \\ National Aeronautics and Space Administration (NASA), John F. Kennedy Space Center, Kennedy Space \\ Center (KSC), Florida 32899
}

(Received 4 October 2004; accepted 3 December 2004; published online 15 February 2005)

\begin{abstract}
The effect of ultraviolet (UV) radiation exposure on the room-temperature hydrogen $\left(\mathrm{H}_{2}\right)$ sensitivity of nanocrystalline indium oxide $\left(\mathrm{In}_{2} \mathrm{O}_{3}\right)$-doped tin oxide $\left(\mathrm{SnO}_{2}\right)$ thin-film gas sensor is investigated in this article. The present sensor is incorporated into microelectromechanical systems device using sol-gel dip-coating technique. The present sensor exhibits a very high sensitivity, as high as 65000 110000 , at room temperature, for $900 \mathrm{ppm}$ of $\mathrm{H}_{2}$ under the dynamic test condition without UV exposure. The $\mathrm{H}_{2}$ sensitivity is, however, observed to reduce to 200 under UV radiation, which is contrary to the literature data, where an enhanced room-temperature gas sensitivity has been reported under UV radiation. The observed phenomenon is attributed to the reduced surface coverage by the chemisorbed oxygen ions under UV radiation, which is in consonance with the prediction of the constitutive equation, proposed recently by the authors, for the gas sensitivity of nanocrystalline semiconductor oxide thin-film sensors. (c) 2005 American Institute of Physics. [DOI: $10.1063 / 1.1851597]$
\end{abstract}

\section{INTRODUCTION}

When a polycrystalline tin oxide $\left(\mathrm{SnO}_{2}\right)$ semiconductor thin film is exposed to air, physisorbed oxygen molecules pick up electrons from the conduction band of $\mathrm{SnO}_{2}$ and change them to $\mathrm{O}_{2}^{-}$ads or $\mathrm{O}_{\text {ads }}^{-}$species. Consequently, a positive space-charge layer forms just below the surface of $\mathrm{SnO}_{2}$ particles, which creates a potential barrier between the particles, increasing the electrical resistance of the $\mathrm{SnO}_{2}$ film. However, when a reducing gas comes in contact with the film, it gets oxidized via reaction with the $\mathrm{O}_{2}^{-}$ads or $\mathrm{O}_{\mathrm{ads}}^{-}$ species, and subsequently, electrons are reintroduced into the electron-depletion layer, leading to a decrease in the potential barrier. $^{1,2}$ The reduction in the electrical resistance of the $\mathrm{SnO}_{2}$ thin film is, hence, taken as a measure to sense the presence of a reducing gas in the environment. The gas sensitivity of the $\mathrm{SnO}_{2}$ thin-film sensor is usually determined by the ratio $R_{\text {air }} / R_{\text {gas }}$, where $R_{\text {gas }}$ and $R_{\text {air }}$ are the sensor resistances in air with and without the reducing gas, respectively.

The maximum gas sensitivity for the nanocrystalline $\mathrm{SnO}_{2}$ sensor is generally observed at higher operating temperatures $\left(250-400{ }^{\circ} \mathrm{C}\right)$. Various parameters such as nanocrystallite size, film thickness and porosity, and amount and nature of dopants, surface oxides, and catalysts are known to be significant in enhancing the gas sensitivity of nanocrystalline $\mathrm{SnO}_{2}$ thin-film sensor in the higher operating temperature range. ${ }^{3,4}$ Nevertheless, the gas sensitivity of the nano-

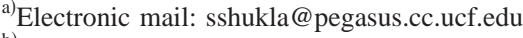

${ }^{\text {b) }}$ Author to whom correspondence should be addressed; electronic mail: sseal@ pegasus.cc.ucf.edu
}

crystalline $\mathrm{SnO}_{2}$ thin-film sensor at lower operating temperatures (typically room temperature) has been very low. Moreover, the large response and recovery times at room temperature have been other major issues associated with the nanocrystalline $\mathrm{SnO}_{2}$ thin-film sensor. As a result, the development of sensitivity-enhancing techniques for room-temperature gas sensing is essential.

Interestingly, few recent investigations ${ }^{5-10}$ do report enhanced gas $\left(\mathrm{CO}\right.$ and $\left.\mathrm{NO}_{2}\right)$ sensitivity of nanocrystalline $\mathrm{SnO}_{2}$ and indium oxide $\left(\mathrm{In}_{2} \mathrm{O}_{3}\right)$ thin-film sensors under ultraviolet (UV) radiation exposure. The maximum enhancement in the gas sensitivity (relative to that in the dark condition) due to UV exposure has been typically observed at room temperature for the nanocrystalline $\mathrm{SnO}_{2}$ thin-film sensor. ${ }^{10}$ The increase in the operating temperature, above room temperature, has been reported to reduce the gas sensitivity under UV exposure. The response and the recovery times are also noted to decrease with UV exposure. In addition to this, a remarkable recovery of titania $\left(\mathrm{TiO}_{2}\right)$-nanotube hydrogen $\left(\mathrm{H}_{2}\right)$ sensor from sensor poisoning (due to various grades of motor oil) through UV-photocatalytic oxidation of the contaminating agents has also been reported recently. ${ }^{11}$ It thus appears that sensing the reducing gases with UV exposure is proving to be an approach for enhancing the roomtemperature gas-sensing characteristics of the nanocrystalline semiconductor oxide thin-film sensors.

The recent report on $\mathrm{TiO}_{2}$-nanotube $\mathrm{H}_{2}$ sensor, however, demonstrated two orders of magnitude decrease in the stabilized original sensor resistance in air $\left(R_{\text {air }}\right)$ under UV exposure relative to that in the dark condition. ${ }^{11}$ According to the 
present authors, if it is assumed that the space-charge layer is eliminated completely in the presence of a reducing gas, then this reduced original sensor resistance, under UV exposure, may have a negative effect on the gas sensitivity $(S$ $\left.=R_{\text {air }} / R_{\text {gas }}\right)$ of the nanocrystalline semiconductor oxide thinfilm sensors relative to that in the absence of UV radiation. However, there is no report in the present literature to justify this hypothesis for the nanocrystalline semiconductor oxide thin-film sensors operating at room temperature. A systematic investigation dealing with the effect of UV exposure on the original sensor resistance, and hence on the gas sensitivity, is lacking in the literature. From this point of view, in the present investigation, we systematically test the nanocrystalline $\mathrm{In}_{2} \mathrm{O}_{3}$-doped $\mathrm{SnO}_{2}$ thin-film sensor to precisely determine the effect of UV-radiation exposure on its roomtemperature $\mathrm{H}_{2}$ gas-sensing characteristics. The choice of $\mathrm{H}_{2}$ as a test gas is driven by its potential applications in the transportation and the power generation industries as well as in launching space vehicles, as required by NASA. We incorporate the nanocrystalline $\mathrm{In}_{2} \mathrm{O}_{3}$-doped $\mathrm{SnO}_{2}$ thin-film sensor into a microelectromechanical systems (MEMS) device for the miniaturization of the sensor, which was lacking in our earlier investigations. ${ }^{12-14}$

\section{EXPERIMENTAL SETUP}

\section{A. Preparation of MEMS device}

3-in. Si (100) wafers and Pyrex glass slides were used as substrates for the sensor fabrication. In the case of Si wafers, thermal oxidation was performed to grow a $1-\mu$ m-thick $\mathrm{SiO}_{2}$ layer, which was used as an insulation layer. Thin chromium $(\mathrm{Cr})(10-20 \mathrm{~nm})$ and gold $(\mathrm{Au})(150-200 \mathrm{~nm})$ films were deposited by thermal evaporation on top of the substrates. Four interdigitated electrodes and one temperature sensor were patterned on the substrate using photolithography and wet chemical etching (Fig. 1). Shipley 1400-27 positive photoresist was used for patterning the electrodes. The gap between the electrodes was kept in the range of $20-50 \mu \mathrm{m}$. After the sol-gel dip coating of the $\mathrm{In}_{2} \mathrm{O}_{3}$-doped $\mathrm{SnO}_{2}$ thin films over the sensor platform, as outlined in Sec. II B, the MEMS device was characterized using the various analytical techniques, and then wire bonded to a ceramic package for final $\mathrm{H}_{2}$ sensing tests. The choice of the substrate for the characterization and for the $\mathrm{H}_{2}$ sensing tests was as per convenience.

\section{B. Deposition of $\operatorname{In}_{2} \mathrm{O}_{3}$-doped $\mathrm{SnO}_{2}$ thin film via sol- gel dip coating}

Tin(IV)-isopropoxide $\left(\mathrm{Sn}\left[\mathrm{OC}_{3} \mathrm{H}_{7}\right]_{4}\right)(10 \mathrm{w} / \mathrm{v} \%)$ in isopropanol $(72 \mathrm{vol} \%)$ and toluene $(18 \mathrm{vol} \%)$ and indium(III)-isopropoxide $\left(\mathrm{Sn}\left[\mathrm{OC}_{3} \mathrm{H}_{7}\right]_{3}\right)$ were purchased from Alafa Aesar (USA) and used as received. The MEMS devices prepared above were utilized for the sol-gel dipcoating experiments.

For synthesizing an $\mathrm{In}_{2} \mathrm{O}_{3}$-doped $\mathrm{SnO}_{2}$ thin film coated on the MEMS device, the solution of tin-isopropoxide in isopropanol and toluene, corresponding to the concentration of $0.23 \mathrm{M}$ of tin-isopropoxide, was used. A calculated amount of indium(III)-isopropoxide was dissolved in this so-

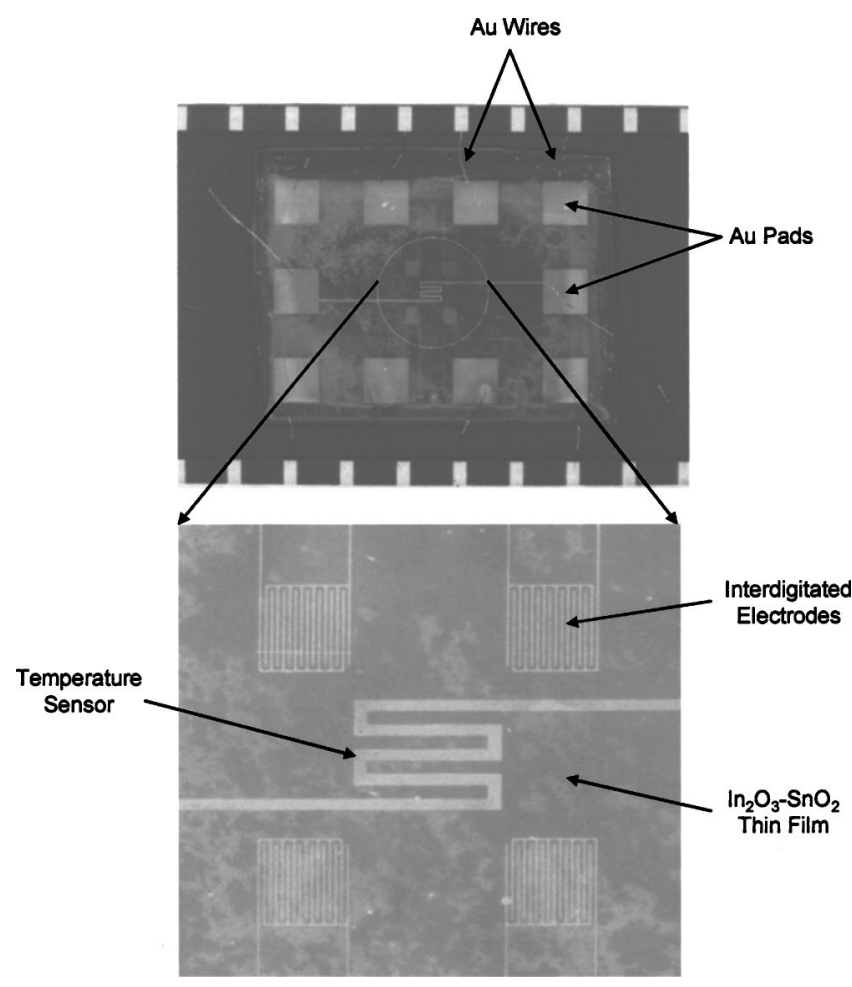

FIG. 1. MEMS device incorporating four interdigitated electrodes and one temperature sensor, which are patterned on the Pyrex glass substrate using photolithography and wet chemical etching. In (a), Au-wire bonds and pads are visible. (b) is an enlarged view of the circled region in (a). The device is sol-gel dip coated with the nanocrystalline Pt-sputtered $\mathrm{In}_{2} \mathrm{O}_{3}$-doped $\mathrm{SnO}_{2}$ thin-film sensor.

lution to obtain the thin films of $\mathrm{SnO}_{2}-6.5 \mathrm{~mol} \% \mathrm{In}_{2} \mathrm{O}_{3}$. The thin films were formed on the MEMS devices using a dip coater with a withdrawal speed of $150 \mathrm{~cm} / \mathrm{min}$. After the dip-coating process, the gel films were dried at $150{ }^{\circ} \mathrm{C}$ for 15-30 min in air. The coated MEMS devices were dip coated again using the same solution under similar processing conditions, and then dried again at $150{ }^{\circ} \mathrm{C}$ for 15-30 min in air. The dried gel films were sputtered with a thin Pt layer for $10 \mathrm{~s}$ using a sputter coater (K350, Emitech Ltd., Ashford, Kent, England). Finally, the Pt-sputtered dried gel films were fired at $400{ }^{\circ} \mathrm{C}$ in air. The coated MEMS devices were heated at a rate of $30^{\circ} \mathrm{C} / \mathrm{min}$ up to the firing temperature, held at that temperature for $60 \mathrm{~min}$, and then cooled to room temperature inside the furnace.

\section{Characterization of Pt-sputtered $\mathrm{In}_{2} \mathrm{O}_{3}$-doped $\mathrm{SnO}_{2}$ thin-film sensor}

The surface chemistry of $\mathrm{In}_{2} \mathrm{O}_{3}$-doped $\mathrm{SnO}_{2}$ thin films dip coated on the MEMS devices was studied using the X-ray photoelectron spectroscopy (XPS) technique utilizing a PHI ESCA spectrometer (model 5400, Perkin-Elmer Corporation, Minnesota), having an energy resolution of $\pm 0.1 \mathrm{eV}$, at a base pressure of $2 \times 10^{-9}$ Torr, using $\mathrm{Mg} K \alpha$ radiation $(1253.6 \mathrm{eV})$. The $\mathrm{x}$-ray power during the analysis was $350 \mathrm{~W}$. Both the survey and the high-resolution narrow scan spectra were recorded at pass energies of 44.75 and $35.75 \mathrm{eV}$, respectively, to achieve the maximum spectral resolution. The binding energy (BE) of the $\mathrm{Au} 4 f_{7 / 2}$ at 
84.0 $\pm 0.1 \mathrm{eV}$ was used to calibrate the BE scale of the spectrometer. Any charging shifts produced by the samples were carefully removed using a BE scale referred to as $\mathrm{C}(1 s) \mathrm{BE}$ of the hydrocarbon part of the adventitious carbon line at $284.6 \mathrm{eV} .{ }^{15}$ Nonlinear least-square curve fitting was performed using a Gaussian/Lorentzian peak shape after the background removal.

The surface morphology of the $\mathrm{In}_{2} \mathrm{O}_{3}$-doped $\mathrm{SnO}_{2}$ thin film was also studied using atomic force microscopy (AFM) (Digital Instrument, Inc.), utilizing a $\mathrm{Si}_{3} \mathrm{~N}_{4}$ tip with a 20-nm radius, in the tapping mode. The average nanocrystallite size and the surface morphology of the $\mathrm{In}_{2} \mathrm{O}_{3}$-doped $\mathrm{SnO}_{2}$ thin film was analyzed using AFM.

Focused ion beam (FIB) (200 TEM, FEI Company, Hillsboro, Oregon) milling technique was performed on the $\mathrm{In}_{2} \mathrm{O}_{3}$-doped $\mathrm{SnO}_{2}$ thin film for the transmission electron microscopy (TEM) sample preparation. The procedure for TEM sample preparation via FIB-milling technique has been described in detail elsewhere ${ }^{16}$ and was adopted in the present investigation. The FIB-milling procedure involved first sputtering of a 100-nm-thick Au-Pd layer followed by the local deposition of a 1-2- $\mu \mathrm{m}$-thick Pt layer over the $\mathrm{In}_{2} \mathrm{O}_{3}$-doped $\mathrm{SnO}_{2}$ thin film in order to protect the film surface from getting destroyed during the FIB-milling operation. Highresolution TEM (HRTEM) (FEI-Philips Tecnai F30) was then used to measure the film thickness.

\section{Preparation of sensor test board incorporating UV- diode lamps}

The sensor test board was designed (at KSC-NASA) using the LPKF CIRCUITCAM 4.0 software and subsequently cut using the LPKF BOARDMASTER 4.0 software on a single-sided $\mathrm{Cu}$-clad prototype boards. The primary sensor test board contained a 32-pin socket assembly, which was placed centered on the test board to facilitate the stimulation of the sensor with the UV-light-emitting-diode (LED) lamp, which is an InGaN LED mounted on a lead frame with clear epoxy lens. On forward bias, it emits a band of visible light that peaks at $375 \mathrm{~nm}$. Edge connectors facilitated the four-wire resistance tests, which were used to characterize the sensor test during an exposure to a specific amount of $\mathrm{H}_{2}$. Figure 2(a) shows a typical sensor-device configuration with an integrated circuit installed into the 32-pin socket.

A daughter board was then fabricated using the same layout and prototyping software, which housed the UV-diode lamps that were to be used to stimulate the sensor. This daughter board was then installed using standoff posts such that the UV-diode lamps were mounted exactly $3 \mathrm{~cm}$ above the sensor surface. A typical photograph of the test board with the daughter board installed inside the test chamber is shown in Fig. 2(b). The UV-light-illuminated sensor surface is clearly visible in this photograph.

\section{E. $\mathrm{H}_{2}$ gas-sensing tests}

\section{Dynamic test condition}

In the present investigation, all $\mathrm{H}_{2}$ gas-sensing tests are conducted in a dynamic condition. In this type of sensor testing, the chamber pressure is reduced and maintained at a
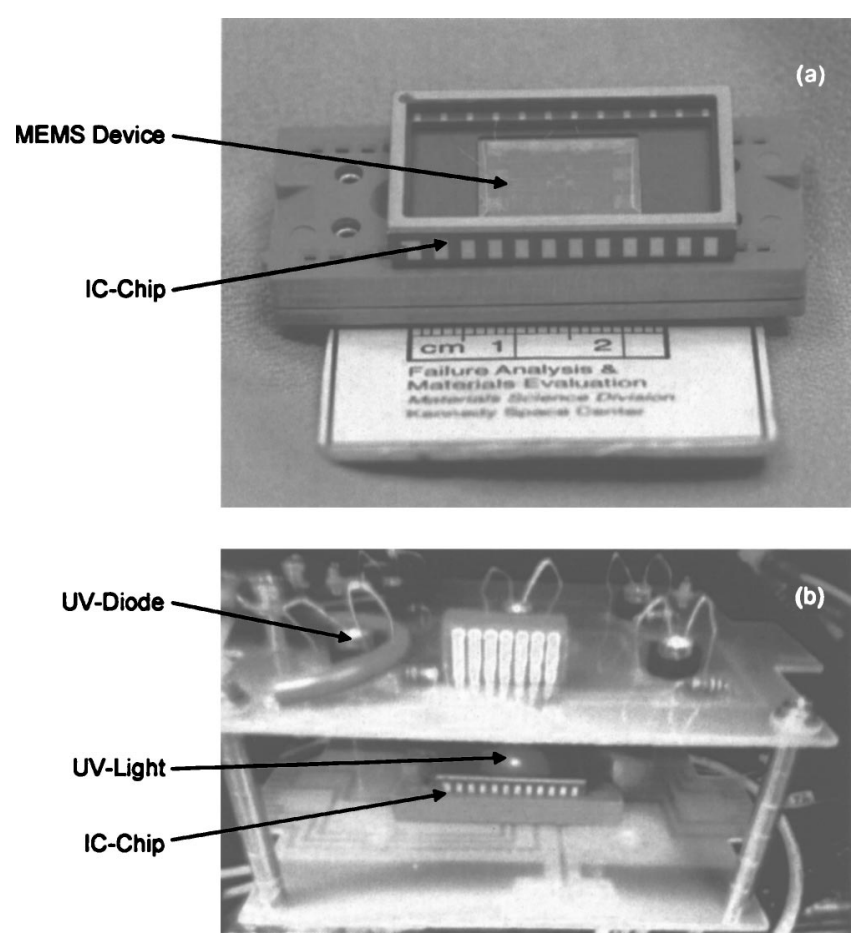

FIG. 2. (a) Typical photograph of a MEMS device incorporating nanocrystalline Pt-sputtered $\mathrm{In}_{2} \mathrm{O}_{3}$-doped $\mathrm{SnO}_{2}$ thin-film sensor installed in 32-pin socket. (b) Sensor test board with an installed daughter board depicting the sensor illumination by UV light.

desired level using the turbo pumps. A mixture of appropriate amounts of nitrogen $\left(\mathrm{N}_{2}\right)$ and $\mathrm{H}_{2}$ is admitted into the test chamber through the respective mass-flow controllers. The $\mathrm{N}_{2}$ gas is used as a carrier gas. The amount of $\mathrm{H}_{2}$ in ppm is calculated using the ratio of the number of moles of $\mathrm{H}_{2}$ admitted into the test chamber per minute to the total number of moles of gas molecules (that is, the summation of the number of moles of $\mathrm{N}_{2}, \mathrm{H}_{2}$, and air) within the test chamber. Thus, in the dynamic test condition, a desired amount of $\mathrm{H}_{2}$ (in ppm) is continuously blown into the test chamber per minute and simultaneously pumped out of the test chamber throughout the test duration. Thus, the dynamic test condition simulates the condition which may be encountered in an actual service application (for example, $\mathrm{H}_{2}$ leakage through a pipe).

\section{Incremental test (steady-state condition)}

This type of sensor test is carried out under the dynamic test condition with and without UV exposure. At the beginning of an incremental test, the original sensor resistance is stabilized completely at 50-Torr air and $22{ }^{\circ} \mathrm{C}$ (this is referred to as a "steady-state condition" hereafter) in the presence of UV radiation. After noting the original sensorresistance values, a mixture of $\mathrm{N}_{2}(15000 \mathrm{ppm})$ and $\mathrm{H}_{2}$ $(18 \mathrm{ppm})$ gases was blown into the test chamber under the dynamic test condition while maintaining the chamber pressure and temperature constant. After a test duration of 60 min (maximum response time), the amount of $\mathrm{H}_{2}$ was increased to $50 \mathrm{ppm}$. A similar procedure was then followed for $100,300,500,700$, and $900 \mathrm{ppm}$ of $\mathrm{H}_{2}$. Thus, in an incremental test, the amount of $\mathrm{H}_{2}$ is incremented after each 
60-min test duration. At the end, turbo pumps were made off and air at 760 Torr was blown into the test chamber. After few minutes, depending on the sensor-resistance value, the turbo pumps were restarted to restore the 50-Torr air pressure, and, hence, the original sensor resistance. An incremental test was also conducted without UV exposure at 50Torr air and $22{ }^{\circ} \mathrm{C}$.

\section{Constant-amount test (steady-state condition)}

Typical cyclic tests were conducted for $900 \mathrm{ppm}$ of $\mathrm{H}_{2}$ at 50-Torr air and $22{ }^{\circ} \mathrm{C}$, with and without UV exposure, with an initial steady-state condition. In this type of sensor test, after stabilizing the original sensor resistance at 50-Torr air and $22{ }^{\circ} \mathrm{C}$ under $\mathrm{UV}$ exposure, a mixture of $\mathrm{N}_{2}$ (15 $000 \mathrm{ppm})$ and $\mathrm{H}_{2}$ (900 ppm) gases is blown continuously into the test chamber under the dynamic test condition. After the maximum response time of $60 \mathrm{~min}$, turbo pumps were made off and air at 50 and 760 Torr was blown into the test chamber in sequence. After a few minutes, depending on the sensor-resistance value, the turbo pumps were started again to restore the 50-Torr air pressure, and, hence, the original sensor resistance. After the completion of the first cycle, the above procedure was repeated for two more times to complete the cyclic test (total number of cycles=3) under UV radiation. A cyclic constant-amount test, for $900 \mathrm{ppm}$ of $\mathrm{H}_{2}$ at 50 -Torr air and $22^{\circ} \mathrm{C}$, was also conducted without UV exposure.

\section{Constant-amount test (unsteady-state condition)}

This type of sensor test (number of cycles=1) was conducted when the sensor resistance decreased continuously during the sensor exposure to UV radiation (this is referred to as an "unsteady-state condition" hereafter). A mixture of $\mathrm{N}_{2}(15000 \mathrm{ppm})$ and $\mathrm{H}_{2}(900 \mathrm{ppm})$ gases was admitted into the test chamber under the dynamic test condition at 50Torr air and $22{ }^{\circ} \mathrm{C}$, when the sensor resistance had dropped to a preselected value (typically 50, 25, 10, and $1.5 \mathrm{M} \Omega$ ). The sensor test was carried out for the constant response time of $60 \mathrm{~min}$. At the end of the sensor test, air at 50 and 760 Torr was blown in sequence into the test chamber in order to restore the initial sensor resistance.

\section{RESULTS}

\section{A. Thin-film characterization}

XPS broad-scan analysis of nanocrystalline $\mathrm{In}_{2} \mathrm{O}_{3}$-doped $\mathrm{SnO}_{2}$ thin-film sensor deposited on the MEMS device is shown in Fig. 3(a). The XPS analysis reveals the presence of $\mathrm{Sn}, \mathrm{In}, \mathrm{O}$, and $\mathrm{Pt}$ as major peaks on the sensor surface. All these peaks have originated from the sol-gel dip-coating process. There is no evidence of the presence of $\mathrm{Si}$ and $\mathrm{Au}$, which may originate from the substrate (MEMS device). The narrow-scan XPS analysis of Sn $(3 d)$, In $(3 d)$, and Pt $(3 d)$ peaks within the $\mathrm{BE}$ range of $480-500 \mathrm{eV}, 435-460 \mathrm{eV}$, and $65-85 \mathrm{eV}$ are presented in Figs. 3(b)-3(d), respectively. In Figs. 3(b) and 3(c), Sn $3 d_{5 / 2}$ and In $3 d_{5 / 2}$ BEs of 487.1 and $445 \mathrm{eV}$ are detected, while in Fig. 3(d), the deconvolu-

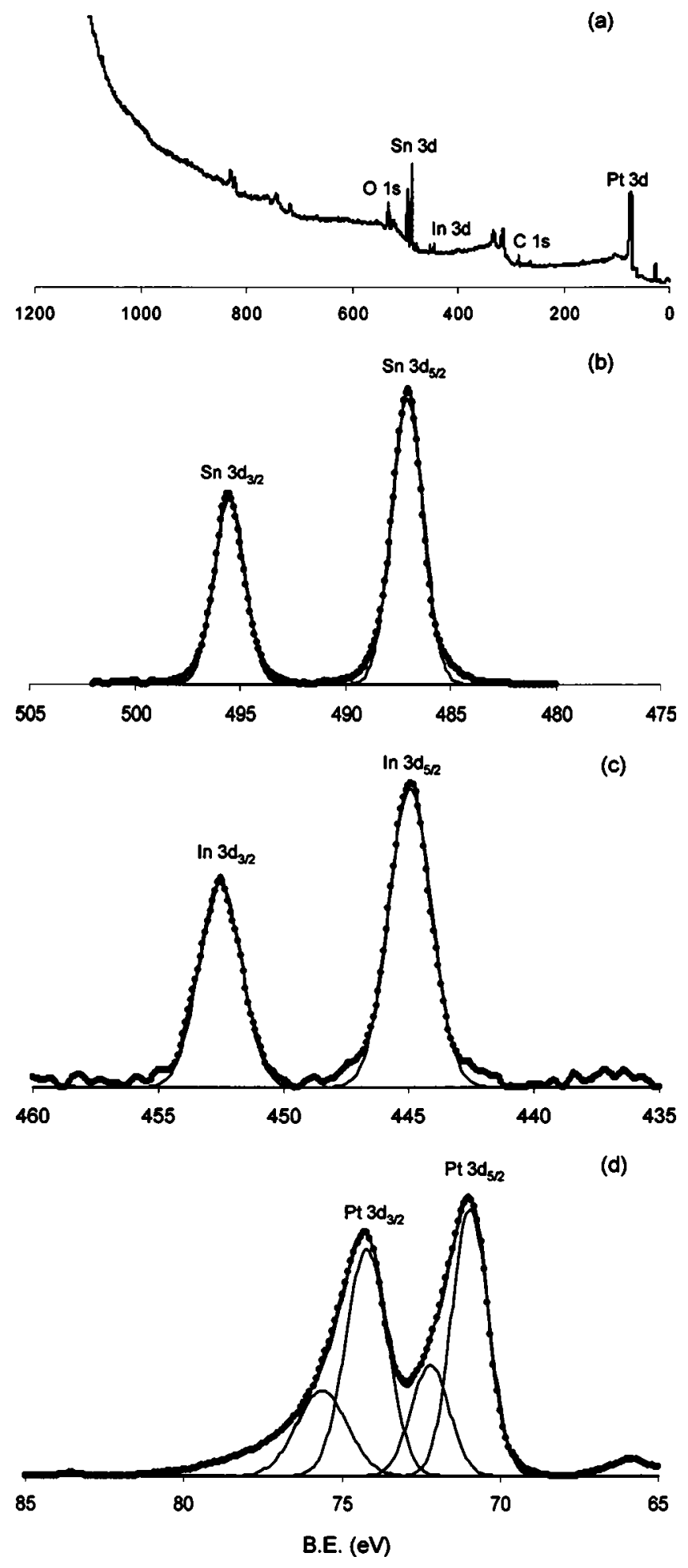

FIG. 3. (a) Broad-scan XPS analysis of nanocrystalline Pt-sputtered $\mathrm{In}_{2} \mathrm{O}_{3}$-doped $\mathrm{SnO}_{2}$ thin-film sensor sol-gel dip coated on the MEMS device. (b)-(d) High-resolution narrow-scan XPS analysis of Sn $(3 d)$, In (3d), and Pt $(3 d)$ peaks.

tion of the Pt $3 d_{5 / 2}$ spectrum reveals the presence of two subpeaks located at BE levels of 71.0 and $72.2 \mathrm{eV}$, respectively.

A typical TEM image of a FIB-milled sample, showing the cross section of the coated MEMS device, is presented in Fig. 4, where four distinct layers are identified using the energy dispersive analysis of $\mathrm{x}$ rays (EDX). The top two 




FIG. 4. Typical TEM image of a FIB-milled sample showing the cross section of Pt-sputtered $\mathrm{In}_{2} \mathrm{O}_{3}$-doped $\mathrm{SnO}_{2}$ thin-film sensor sol-gel dip coated on the MEMS device. $\mathrm{Si} / \mathrm{SiO}_{2}$ substrate, Au electrode, $\mathrm{In}_{2} \mathrm{O}_{3}-\mathrm{SnO}_{2}$ sensor, and $\mathrm{Au}-\mathrm{Pd}$ and $\mathrm{Pt}$ protective layers.

layers, $\mathrm{Pt}$ and $\mathrm{Au}-\mathrm{Pd}$, originate from the FIB-milling procedure while the bottom two layers, $\mathrm{Si} / \mathrm{SiO}_{2}$ and $\mathrm{Au}$, originate from the preparation of the MEMS device (substrate). The sol-gel dip-coated $\mathrm{In}_{2} \mathrm{O}_{3}$-doped $\mathrm{SnO}_{2}$ layer is seen as an intermediate layer with a thickness of $125-150 \mathrm{~nm}$. Few cracks are also visible within the film.

The AFM analysis of nanocrystalline $\mathrm{In}_{2} \mathrm{O}_{3}$-doped $\mathrm{SnO}_{2}$ thin-film sensor deposited on the MEMS device is presented in Fig. 5 at low and high magnifications. The sol-gel dipcoated thin film appears to be porous at the nanometer level, in agreement with the TEM analysis. Moreover, the thin film appears to consist of chunks of agglomerated nanoparticles [Fig. 5(a)]. The average chunk size [Fig. 5(a)] and the average nanoparticle size [Fig. 5(b)] are noted to be $1 \mu \mathrm{m}$ and $50 \mathrm{~nm}$, respectively, while the pore size [Fig. 5(b)] is noted to be $500 \mathrm{~nm}-2 \mu \mathrm{m}$.
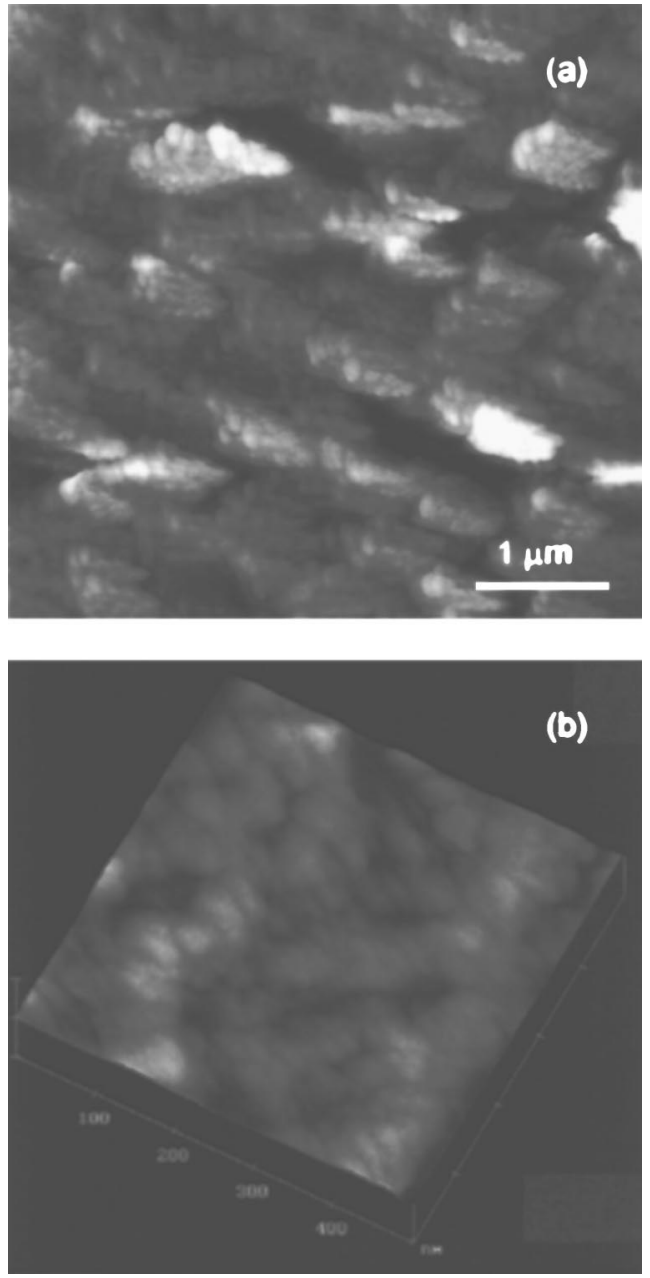

FIG. 5. AFM analysis of nanocrystalline Pt-sputtered $\mathrm{In}_{2} \mathrm{O}_{3}$-doped $\mathrm{SnO}_{2}$ thin-film sensor sol-gel dip coated on the $\mathrm{Si} / \mathrm{SiO}_{2}$ wafer at low (a) and high (b) magnifications. In (a), a few cracks are visible on the surface of the thin film with length $=1-2 \mu \mathrm{m}$ and width $=500 \mathrm{~nm}$. Chunks of nanoparticles with an average size of $1 \mu \mathrm{m}$ are visible in (a) with an average nanoparticle size of $50 \mathrm{~nm}(\mathrm{~b})$.

\section{B. $\mathrm{H}_{2}$ gas-sensing tests at room temperature 1. With UV on (steady-state condition)}

The continuous variation in the sensor resistance as a function of time for the stepwise increase in the amount of



FIG. 6. Sensor response, at room temperature, to the incremental test conducted under the dynamic test condition within the range of $18-900 \mathrm{ppm}_{2}$ with UV exposure. 


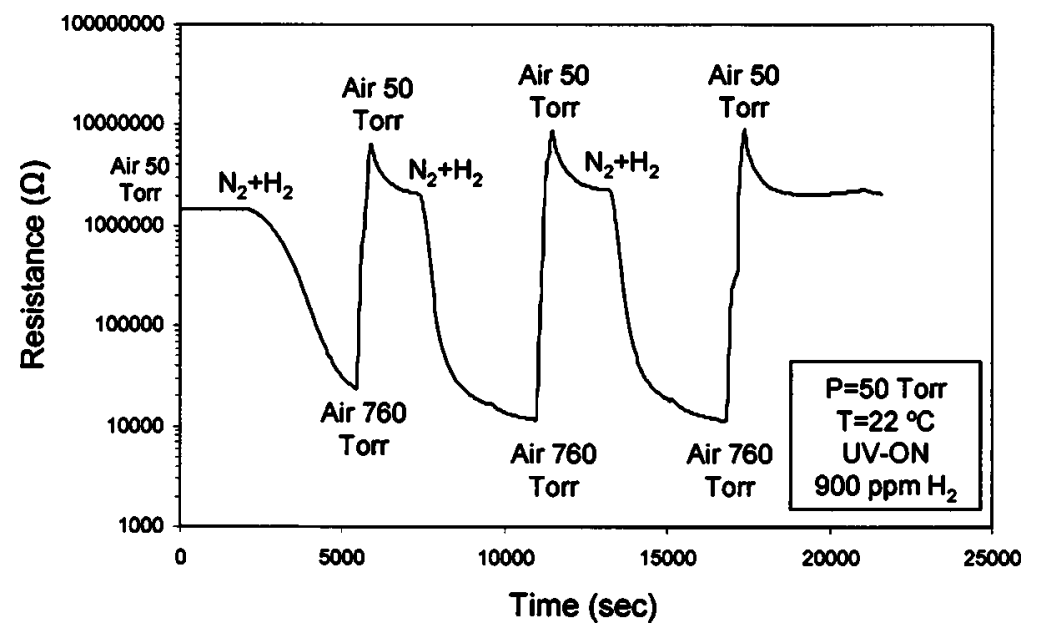

FIG. 7. Cyclic sensor response, at room temperature, to the constant-amount test conducted under the dynamic test condition for $900 \mathrm{ppm} \mathrm{H}_{2}$ with UV exposure.
$\mathrm{H}_{2}$ (incremental test), within the range of $18-900 \mathrm{ppm}$ with UV exposure, is shown in Fig. 6. In the presence of UV radiation, at 50-Torr air and $22{ }^{\circ} \mathrm{C}$, the sensor resistance is stabilized at $1.5 \mathrm{M} \Omega$. For the constant response time of $60 \mathrm{~min}$, the sensor resistance decreases continuously as the amount of $\mathrm{H}_{2}$ is increased within the range of $18-900 \mathrm{ppm}$. At the end of an incremental test, it drops nearly two orders of magnitude below the original sensor resistance. Blowing the air at 760 Torr rapidly increases the sensor resistance, which shoots up above the original value. To restore the original sensor resistance, the chamber pressure is reduced to 50 Torr, which results in a sudden decrease in the sensor resistance and its subsequent gradual stabilization at the original resistance of $1.5 \mathrm{M} \Omega$. A type of recovery technique is demonstrated, which is termed here as a "nonconventional recovery" technique.

A typical cyclic constant-amount test (number of cycles=3), conducted for $900 \mathrm{ppm}_{2}$ under the dynamic test condition, at 50-Torr air and $22{ }^{\circ} \mathrm{C}$, is shown in Fig. 7. In this cyclic test, the response time is kept constant to $60 \mathrm{~min}$ for all three cycles. The total drop in the sensor resistance is observed to be larger for the second and third cycles relative to that in the first cycle. The drop of two orders of magnitude in the sensor resistance (Fig. 7) is consistent with a similar drop observed during an incremental test (Fig. 6). The nonconventional recovery technique is successfully demonstrated in this test as well.

\section{With UV off (steady-state condition)}

As shown in Fig. 8, turning off the UV radiation, at 50 -Torr air and $22^{\circ} \mathrm{C}$, results in a gradual increase in the sensor resistance from 1.5 to $850 \mathrm{M} \Omega$ in almost $40 \mathrm{~h}$.

The continuous variation in the sensor resistance as a function of time for the stepwise increase in the amount of $\mathrm{H}_{2}$ (incremental test), within the range of 18-900 ppm without UV exposure, is shown in Fig. 9. In the absence of UV radiation, at 50-Torr air and $22{ }^{\circ} \mathrm{C}$, the sensor resistance is stabilized at a very high resistance value of $850 \mathrm{M} \Omega$. For the constant response time of $60 \mathrm{~min}$, the sensor resistance decreases continuously as the amount of $\mathrm{H}_{2}$ is increased within the range of 18-900 ppm, and at the end of an incremental test, it drops four- to five orders of magnitude below the original sensor resistance. Blowing the air at 760 Torr rapidly increases the sensor resistance, which stabilizes slightly below the original value.

A typical cyclic constant-amount test (number of cycles $=3$ ), conducted for $900 \mathrm{ppm} \mathrm{H}_{2}$ under the dynamic test condition, at 50-Torr air and $22{ }^{\circ} \mathrm{C}$, is shown in Fig. 10. In this cyclic test, the response time is kept constant to $60 \mathrm{~min}$ for all three cycles. The total drop in the sensor resistance is again observed to be larger for the second and third cycles relative to that in the first cycle. The drop of four- to five orders of magnitude in the sensor resistance (Fig. 10) is consistent with a similar drop observed during an incremental test (Fig. 9). In Fig. 10, at the end of each cycle,

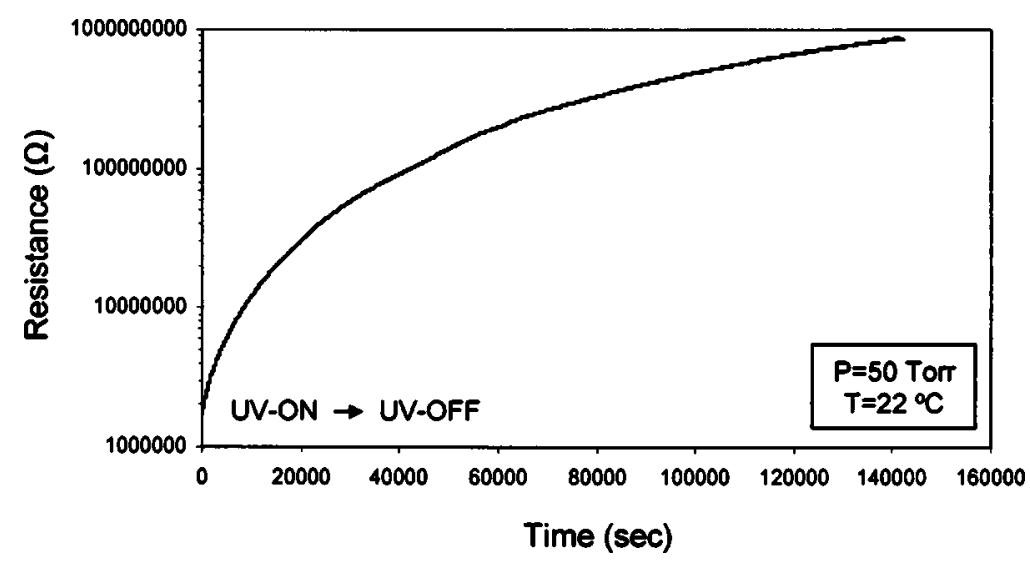

FIG. 8. Variation in the room-temperature sensor resistance in air after switching off the UV radiation from the initial on condition. 


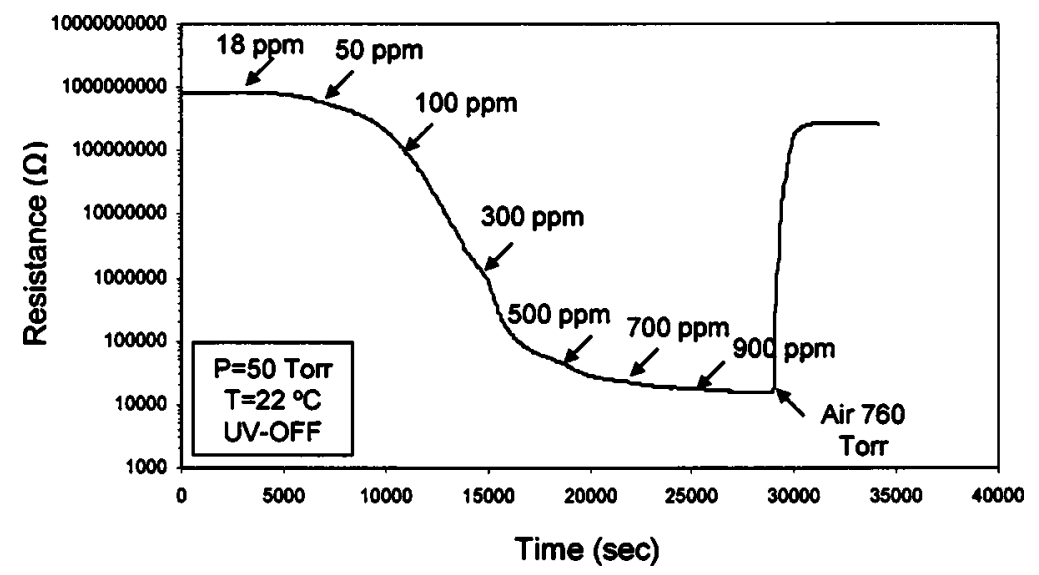

FIG. 9. Sensor response, at room temperature, to the incremental test conducted under the dynamic test condition within the range of $18-900 \mathrm{ppm}_{2}$ without $\mathrm{UV}$ exposure.

after blowing 760-Torr air, the sensor resistance stabilizes slightly below the original sensor resistance. The latter is, however, regained after starting the turbo pumps to restore the 50-Torr air pressure.

\section{With UV off to UV on (unsteady-state condition)}

The variation in the sensor resistance as a function of time, after exposing the sensor to UV radiation, at 50-Torr air and $22{ }^{\circ} \mathrm{C}$, is shown in Fig. 11. The sensor resistance drops instantaneously from $1.0 \mathrm{G} \Omega$ to $100 \mathrm{M} \Omega$, and then decreases gradually to attain a steady-state value of $1.5 \mathrm{M} \Omega$ over the period of $48 \mathrm{~h}$. The gradual decrease in the sensor resistance due to UV exposure is termed here as an unsteadystate condition.

The sensor response to $900 \mathrm{ppm}$ of $\mathrm{H}_{2}$ (constant-amount test) at 50-Torr air and $22{ }^{\circ} \mathrm{C}$, under the unsteady-state condition is presented in Fig. 12. In Figs. 12(a)-12(c), $\mathrm{H}_{2}$ is introduced into the test chamber when the sensor resistance has dropped to 50, 25, and $10 \mathrm{M} \Omega$ under UV exposure. After the constant response time of $60 \mathrm{~min}$, an almost equivalent sensor resistance in the presence of $\mathrm{H}_{2}$ is observed under all test conditions. The $\mathrm{H}_{2}$ flow is then stopped and air at 50 Torr is blown into the test chamber, which results in the very slow recovery of the sensor resistance. However, when air at 760 Torr is blown in, the original sensor resistance is recovered within 20-30 min.

\section{DISCUSSION}

\section{A. Synthesis of nanocrystalline $\operatorname{In}_{2} \mathrm{O}_{3}$-doped $\mathrm{SnO}_{2}$ thin film}

Nanocrystalline semiconductor $\mathrm{In}_{2} \mathrm{O}_{3}$-doped $\mathrm{SnO}_{2}$ thin film, having a thickness of $125-150 \mathrm{~nm}$ and an average nanoparticle size of $50 \mathrm{~nm}$, has been successfully synthesized in this investigation using the sol-gel dip-coating process. As shown in our earlier investigation, ${ }^{12}$ nanoparticles with an average size of $50 \mathrm{~nm}$ are the aggregates of nanocrystallities with a size of 6-8 nm. The formation of $\mathrm{In}_{2} \mathrm{O}_{3}$-doped $\mathrm{SnO}_{2}$ thin film via sol-gel process involves the hydrolysis of tin(IV)- and indium(III)-isopropoxide via reaction with the atmospheric moisture over the MEMS device, which results in the formation of $\mathrm{In}(\mathrm{OH})_{3}$-doped $\mathrm{Sn}(\mathrm{OH})_{4}$ gel. This gel undergoes condensation reaction upon drying at $150{ }^{\circ} \mathrm{C}$ to form an amorphous thin film of $\mathrm{In}_{2} \mathrm{O}_{3}$-doped $\mathrm{SnO}_{2}$ nanoparticles. The amorphous thin film, however, crystallizes upon firing at $400{ }^{\circ} \mathrm{C}$ producing nanocrystalline semiconductor $\mathrm{In}_{2} \mathrm{O}_{3}$-doped $\mathrm{SnO}_{2}$ thin film.

The subsequent XPS analysis reveals the $\mathrm{Sn} 3 d_{5 / 2} \mathrm{BE}$ and In $3 d_{5 / 2} \mathrm{BE}$ of 487.1 and $445.0 \mathrm{eV}$, which correspond to $\mathrm{Sn}^{4+}$ and $\mathrm{In}^{3+}$ oxidation states. ${ }^{17}$ From the broad-scan XPS spectrum, the atomic concentrations of $\mathrm{Sn}, \mathrm{In}$, and $\mathrm{O}$ within the thin-film sensor are found to be $30 \%, 4 \%$, and $66 \%$, respectively, which are in reasonable agreement with the initial precursor concentrations, which were selected to produce



FIG. 10. Cyclic room-temperature sensor response to the constant-amount test conducted under the dynamic test condition for $900 \mathrm{ppm} \mathrm{H}_{2}$ without UV exposure. 



FIG. 11. Variation in the room-temperature sensor resistance in air after switching on the UV radiation from the initial off condition.
FIG. 12. Sensor response, at room temperature, to the constant-amount test conducted under the dynamic test condition for $900 \mathrm{ppm} \mathrm{H}_{2}$ under the unsteady-state condition caused by UV exposure. In (a)-(c), a mixture of $\mathrm{N}_{2}$ and $\mathrm{H}_{2}$ gases is introduced into the test chamber, when the sensor resistance has dropped to 50,25, and $10 \mathrm{M} \Omega$, respectively, due to UV exposure. 


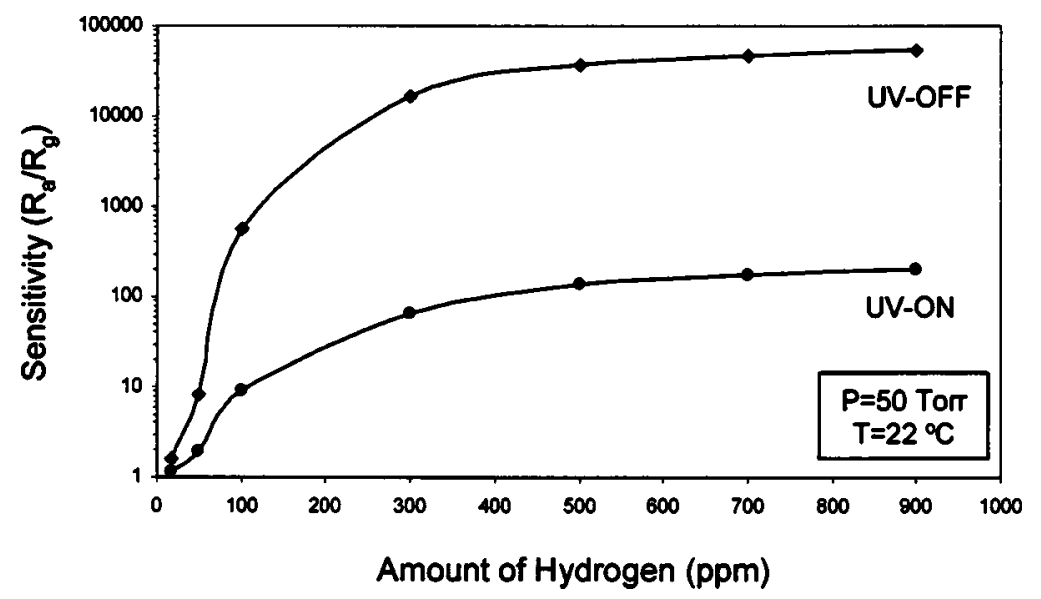

FIG. 13. Comparison of the $\mathrm{H}_{2}$ sensitivity of nanocrystalline Pt-sputtered $\mathrm{In}_{2} \mathrm{O}_{3}$-doped $\mathrm{SnO}_{2}$ thin-film sensor as a function of the amount of $\mathrm{H}_{2}$ with and without $\mathrm{UV}$ exposure.

$\mathrm{SnO}_{2}$ thin film doped with $6.5 \mathrm{~mol} \% \mathrm{In}_{2} \mathrm{O}_{3}$. The two subpeaks located at BE levels of 71.0 and $72.2 \mathrm{eV}$, obtained after the deconvolution of the $\mathrm{Pt} 3 d_{5 / 2}$ spectrum, correspond to $\mathrm{Pt}^{0}$ and $\mathrm{Pt}(\mathrm{OH})_{2}$, respectively. ${ }^{17}$ It appears that the atmospheric moisture is adsorbed over the Pt catalyst resulting in the formation of $\mathrm{Pt}(\mathrm{OH})_{2}$. Although the adsorbed moisture may passivate the catalyst surface, the amount of $\operatorname{Pt}(\mathrm{OH})_{2}$ is less than that of an active $\mathrm{Pt}^{0}$ catalyst. Thus, the successful synthesis of the Pt-sputtered nanocrystalline $\mathrm{In}_{2} \mathrm{O}_{3}$-doped $\mathrm{SnO}_{2}$ thin-film sensor incorporated into the MEMS device is confirmed via AFM, FIB-TEM, and XPS analyses.

\section{B. Sensing $\mathrm{H}_{2}$ at room temperature}

\section{Effect of $U V$ radiation on $\mathrm{H}_{2}$ gas sensitivity}

The nanocrystalline $\mathrm{In}_{2} \mathrm{O}_{3}$-doped $\mathrm{SnO}_{2}$ thin-film sensor incorporated into the MEMS device was then utilized to sense $\mathrm{H}_{2}$ at room temperature. Moreover, the effect of UV radiation on the $\mathrm{H}_{2}$ gas sensitivity and the response time of the present thin-film sensor was determined using two different sensor tests (incremental and constant-amount tests).

a. Analysis of incremental test results (steady-state condition). The variation in the $\mathrm{H}_{2}$ sensitivity as a function of the amount of $\mathrm{H}_{2}$, obtained with and without UV exposure, as derived from the incremental tests (Figs. 6 and 9), is compared in Fig. 13. A near-parabolic (or sigmoidal) variation in the $\mathrm{H}_{2}$ sensitivity as a function of the amount of $\mathrm{H}_{2}$ is observed under both the conditions. With UV exposure, the $\mathrm{H}_{2}$ sensitivity increases from 1.2 to 67 with increasing the amount of $\mathrm{H}_{2}$ within the range of $18-300 \mathrm{ppm}$, and then approaches slowly the maximum value of 200 observed for $900 \mathrm{ppm} \mathrm{H}_{2}$. On the other hand, without UV exposure, the $\mathrm{H}_{2}$ sensitivity increases rapidly from 1.6 to 16400 with increasing the amount of $\mathrm{H}_{2}$ within the range of $18-300 \mathrm{ppm}$, and then approaches slowly the maximum value of 54000 observed for $900 \mathrm{ppm} \mathrm{H}_{2}$. The incremental test results, under the initial steady-state condition, thus strongly suggests successful sensing of $\mathrm{H}_{2}$ with high sensitivity at room temperature. Moreover, the $\mathrm{H}_{2}$ gas sensitivity of the present sensor is higher without UV exposure than that with UV exposure within the range of $18-900 \mathrm{ppm}$ of $\mathrm{H}_{2}$.

b. Analysis of constant-amount test results (steady-state condition). The variation in the $\mathrm{H}_{2}$ sensitivity $\left(900\right.$ ppm $\mathrm{H}_{2}$ ) as a function of time (derived from Figs. 7 and 10), observed for three different cycles, with and without UV exposure, is shown in Figs. 14(a) and 14(b), respectively. For both with and without UV exposure, the $\mathrm{H}_{2}$ sensitivity in the first cycle increases with time in a sigmoidal fashion; however, the shape changes to near parabolic in the next two cycles. With UV exposure [Fig. 14(a)] for the constant response time of $60 \mathrm{~min}, \mathrm{H}_{2}$ sensitivity values of 62,174 , and 200 are observed for the first, second, and third cycles, respectively. On the other hand, without UV exposure [Fig. 14(b)], for the constant response time of $60 \mathrm{~min}, \mathrm{H}_{2}$ sensitivity values of 65000,110000 , and 90000 are observed for the first, second, and third cycles, respectively. Comparison of Figs. 14(a) and 14(b) strongly suggests that the $\mathrm{H}_{2}$ sensitivity improves drastically after the first cycle for both with and without UV exposure. Importantly, the $\mathrm{H}_{2}$ sensitivity of the present sensor is much larger without UV exposure relative to that with UV exposure, which is in good agreement with incremental test results. The recovery time of 20-30 min is noted, at room temperature, under both the conditions using the nonconventional recovery technique.

Thus, the incremental- and the constant-amount test results show very high $\mathrm{H}_{2}$ sensitivity, at room temperature, without UV exposure. The reason for observing a very high $\mathrm{H}_{2}$ sensitivity, in the absence of UV radiation, is discussed later.

\section{Effect of $U V$ on response time}

The variation in the response time for different $\mathrm{H}_{2}$ sensitivity values (derived from Fig. 14), observed with and without UV exposure, is shown in Figs. 15(a) and 15(b), respectively. With UV exposure [Fig. 15(a)] in the first cycle, the response time increases from 22 to 55 min as the $\mathrm{H}_{2}$ sensitivity increases within the range of 2-50. However, for the same sensitivity range, the response time varies between 3-15 min for the second and the third cycles. Thus, an improved response time [Fig. 15(a)] is noted after the first cycle, with UV exposure. On the other hand, without UV exposure [Fig. 15(b)] in the first cycle, the response time increases from 27 to $45 \mathrm{~min}$ as the sensitivity increases within the range of 10-1000. However, for the same sensitivity range, the response time varies between 3-12 min for the second and the third cycles. Thus, an improved response time [Fig. 15(b)] is noted in the second and third cycles, in 



FIG. 14. Variation in the $\mathrm{H}_{2}$ sensitivity of nanocrystalline Pt-sputtered $\operatorname{In}_{2} \mathrm{O}_{3}$-doped $\mathrm{SnO}_{2}$ thin-film sensor as a function of time (for constant response time of $60 \mathrm{~min}$ ) for different cycles, with (a) and without (b) UV exposure. (a) and (b) are derived using Figs. 7 and 10 , respectively. the absence of UV exposure, similar to the behavior noted with UV exposure. Interestingly, a lower response time for a much higher sensitivity range is noted without UV exposure than that with UV exposure.
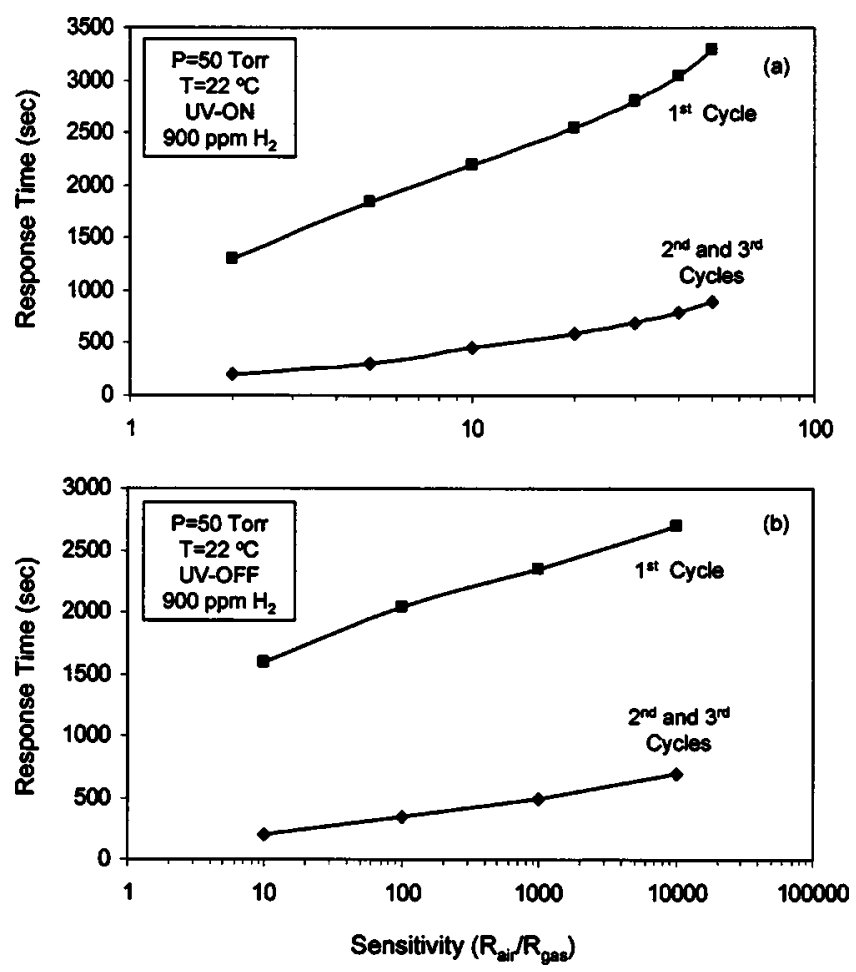

FIG. 15. Variation in the response time as a function of the $\mathrm{H}_{2}$ sensitivity of nanocrystalline Pt-sputtered $\mathrm{In}_{2} \mathrm{O}_{3}$-doped $\mathrm{SnO}_{2}$ thin-film sensor for different cycles, with (a) and without (b) UV exposure. (a) and (b) are derived using Figs. 14(a) and 14(b), respectively.
In Fig. 16, the response time observed with and without UV exposure is compared within the $\mathrm{H}_{2}$ sensitivity range of 2-50. For this sensitivity range, with UV exposure, the response time lies within the range of 3-15 min, while without UV exposure, it lies within the range of 2-5 min. Thus, an improved sensor response time is certainly observed without UV exposure relative to that with UV exposure.

It appears from the present analysis that the present sensor exhibits a maximum $\mathrm{H}_{2}$ sensitivity and a minimum response time without UV exposure. Hence, an exposure to UV radiation is not a favorable condition for the present sensor to improve its room-temperature $\mathrm{H}_{2}$ sensing characteristics, as reported earlier by others. ${ }^{5-10}$

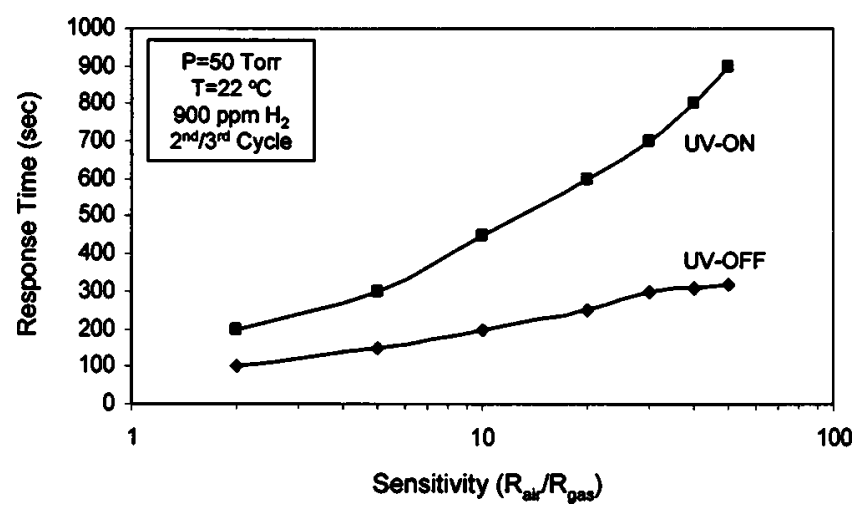

FIG. 16. Comparison of response time as a function of the $\mathrm{H}_{2}$ sensitivity of nanocrystalline Pt-sputtered $\mathrm{In}_{2} \mathrm{O}_{3}$-doped $\mathrm{SnO}_{2}$ thin-film sensor with and without UV exposure. 



FIG. 17. (a) Variation in the $\mathrm{H}_{2}$ sensitivity of nanocrystalline Pt-sputtered $\mathrm{In}_{2} \mathrm{O}_{3}$-doped $\mathrm{SnO}_{2}$ thin-film sensor as a function of time (a) and original sensor resistance (b), as observed under the "unsteady-state condition" caused by UV exposure.

\section{Analysis of constant-amount test results (unsteady-state condition)}

The present sensor exhibits a very high stable original resistance $(0.85-1.8 \mathrm{G} \Omega)$ at 50 -Torr air and $22{ }^{\circ} \mathrm{C}$ without UV exposure. Under these conditions, a very high $\mathrm{H}_{2}$ sensitivity value of 110000 is noted for $900 \mathrm{ppm} \mathrm{H}_{2}$. In the presence of UV radiation, however, the original sensor resistance drops gradually and stabilizes to $1.5 \mathrm{M} \Omega$ (Fig. 11). Under this stabilized condition, a very low $\mathrm{H}_{2}$ sensitivity value of 200 is noted for $900 \mathrm{ppm} \mathrm{H}_{2}$. This indicates that, an exposure to UV radiation not only reduces the $\mathrm{H}_{2}$ sensitivity but also its original sensor resistance. This also suggests that the decrease in the original sensor resistance under UV exposure is primarily responsible for the decrease in the $\mathrm{H}_{2}$ sensitivity at room temperature. In order to confirm the relationship between the original sensor resistance and the $\mathrm{H}_{2}$ sensitivity of the present sensor, different sets of constant-amount tests were conducted (Fig. 12) at room temperature under the unsteady-state condition induced by the sensor exposure to UV radiation.

The sigmoidal variation in the $\mathrm{H}_{2}$ sensitivity as a function of time (obtained from Fig. 12), observed under unsteady-state conditions, is presented in Fig. 17(a) for different original sensor-resistance values. It is noted that the $\mathrm{H}_{2}$ sensitivity shifts downwards and to the right-hand side with decreasing original sensor resistance under a continuous UV exposure. In other words, the $\mathrm{H}_{2}$ sensitivity decreases and the response time increases with decreasing the original sensor resistance under UV exposure. As shown in Fig. 17(b), for the constant response time of $60 \mathrm{~min}$, the $\mathrm{H}_{2}$ sensitivity is observed to decrease continuously with decreasing original sensor resistance under the unsteady-state condition caused by UV exposure. This strongly suggests that the $\mathrm{H}_{2}$ sensitivity of the present sensor is dependent on the original sensor resistance. The UV exposure reduces the original sensor resistance, which in turn, decreases the $\mathrm{H}_{2}$ sensitivity. The theoretical basis for this type of sensor behavior can be explained based on the constitutive equation for the gas sensitivity of nanocrystalline semiconductor oxide thin-film sensor proposed recently by the present authors. ${ }^{18-20}$

\section{Theoretical basis}

The constitutive equation for the gas sensitivity $(S)$ of nanocrystalline semiconductor oxide thin-film sensor is given by the relationship of the form ${ }^{18-20}$

$$
S=\frac{A_{2}}{D} \sqrt{\frac{4 \varepsilon_{r} \varepsilon_{0} k}{q^{2}}} \frac{\sqrt{T}}{n_{b}^{1.5}} C^{n} \exp \left(\frac{q^{2}}{2 \varepsilon_{r} \varepsilon_{0} k} \cdot \frac{\left[O^{-}\right]^{2}}{\left[V_{\mathrm{O}}\right] T}\right),
$$

where $A_{2}$ is a constant, $D$ the nanocrystallite size, $\varepsilon_{r} \varepsilon_{0}$ the permittivity of the sensor, $k$ the Boltzmann constant, $q$ the electronic charge, $T$ the absolute temperature, $n_{b}$ the chargecarrier concentration within the bulk, $C$ the amount of reducing gas (in ppm), $n$ the gas exponent, $\left[\mathrm{O}^{-}\right]$the occupied density of surface states, and $\left[V_{\mathrm{O}}\right]$ the oxygen-ion-vacancy concentration. If we assume that the space-charge layer is completely eliminated in the presence of a reducing gas, then 


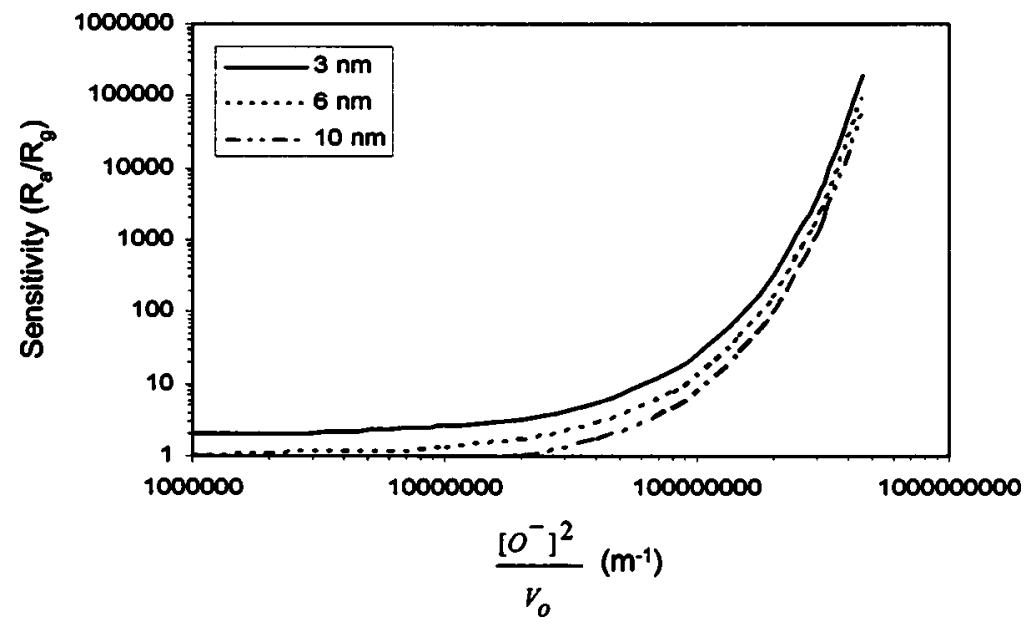

FIG. 18. Theoretical prediction of the variation in the $\mathrm{H}_{2}$ sensitivity of nanocrystalline Pt-sputtered $\mathrm{In}_{2} \mathrm{O}_{3}$-doped $\mathrm{SnO}_{2}$ thin-film sensor as a function of the exponential parameter $\left[\mathrm{O}^{-}\right]^{2} / V_{\mathrm{O}}$ for different nanocrystallite sizes.

the constitutive equation can be written in the simplified form as

$$
S=\frac{2 d}{D} \exp \left(\frac{q^{2}}{2 \varepsilon_{r} \varepsilon_{0} k} \frac{\left[O^{-}\right]^{2}}{\left[V_{\mathrm{O}}\right] T}\right),
$$

where $d$ is the space-charge layer thickness. Assuming that $d=3 \mathrm{~nm}^{21}$ and $T=298 \mathrm{~K}$, the theoretical variation in the $\mathrm{H}_{2}$ sensitivity as a function of the parameter $\left[\mathrm{O}^{-}\right]^{2} /\left[\mathrm{V}_{\mathrm{O}}\right]$, derived using Eq. (2), is plotted in Fig. 18 for different nanocrystallite sizes. The constitutive equation predicts that the gas sensitivity of the nanocrystalline semiconductor oxide thin-film sensor increases slowly with increasing the value of the parameter $\left[O^{-}\right]^{2} /\left[V_{\mathrm{O}}\right]$ within the range of $10^{6}-2 \times 10^{7} \mathrm{~m}^{-1}$. However, above this range, the gas sensitivity increases rapidly with further increase in the value of the parameter $\left[O^{-}\right]^{2} /\left[V_{\mathrm{O}}\right]$. Typically, the gas sensitivity value of 110000 may be observed for a 3-nm nanocrystallite size when the value of the parameter $\left[O^{-}\right]^{2} /\left[V_{\mathrm{O}}\right]$ is equal to $4.5 \times 10^{7} \mathrm{~m}^{-1}$. Moreover, Fig. 18 also indicates that the decrease in the value of the parameter $\left[\mathrm{O}^{-}\right]^{2} /\left[\mathrm{V}_{\mathrm{O}}\right]$ from $4.5 \times 10^{7}$ to 1.5 $\times 10^{7} \mathrm{~m}^{-1}$ decreases the gas sensitivity from 110000 to 100 .

Further, from the definition of the gas sensitivity and Eq. (2), we get

$$
R_{\text {air }}=R_{\text {gas }} \frac{2 d}{D} \exp \left(\frac{q^{2}}{2 \varepsilon_{r} \varepsilon_{0} k} \frac{\left[O^{-}\right]^{2}}{\left[V_{\mathrm{O}}\right] T}\right) .
$$

Since $R_{\text {gas }}$ is observed to be almost equal for different original sensor-resistance values (Fig. 12), it can be assumed to be a constant in Eq. (3). Equations (2) and (3), thus, suggest that both the $\mathrm{H}_{2}$ sensitivity and the original sensor resistance are dependent on the value of the parameter $\left[\mathrm{O}^{-}\right]^{2} /\left[\mathrm{V}_{\mathrm{O}}\right]$. According to Eq. (3), the decrease in the value of the parameter $\left[\mathrm{O}^{-}\right]^{2} /\left[V_{\mathrm{O}}\right]$ decreases the original sensor resistance in air, which in turn, reduces the $\mathrm{H}_{2}$ gas sensitivity [Eq. (2) and Fig. $17(\mathrm{~b})]$.

The decrease in the $\mathrm{H}_{2}$ sensitivity due to UV exposure, as observed in the present investigation, can now be very well explained on the basis of the above theoretical analysis. A very high $\mathrm{H}_{2}$ gas sensitivity, as high as 110000 , is observed for $900 \mathrm{ppm} \mathrm{H}_{2}$, without UV exposure. A very high original sensor resistance $(0.85-1.0 \mathrm{G} \Omega)$ is noted under this condition. The very high $\mathrm{H}_{2}$ sensitivity associated with the very high original sensor resistance appears to be mainly due to the very high value of the parameter $\left[O^{-}\right]^{2} /\left[V_{\mathrm{O}}\right]$ associated with the present sensor without UV exposure. There are two important synthesis variables which may contribute to the very high value of the parameter $\left[\mathrm{O}^{-}\right]^{2} /\left[\mathrm{V}_{\mathrm{O}}\right]$. The first parameter is the small nanocrystalline size (typically less than $10 \mathrm{~nm}),{ }^{22}$ and the second is the trivalent $\operatorname{~In~}^{3+}$ ions, which are doped in the $\mathrm{SnO}_{2}$ lattice. Both of these factors enhance the lattice oxygen-ion vacancy concentration at room temperature, which in turn, is responsible for the chemisorption of the excess amount of oxygen ions on the surface. The high concentration of surface-adsorbed oxygen ions increases both the original sensor resistance and the $\mathrm{H}_{2}$ sensitivity.

With UV exposure, an instantaneous drop in the original sensor resistance is observed, which corresponds to the transition of valence-band electrons to the conduction band. ${ }^{11}$ This instantaneous decrease in the sensor resistance is then followed by a gradual decrease over a long period of time (Fig. 11), which is due to the desorption of the surfaceadsorbed oxygen ions under the continuous UV exposure. The desorption of the chemisorbed oxygen ions takes place mainly due to the generation of excess holes in the valence band $\left(h_{\mathrm{vb}}^{+}\right)$, which find access to the surface, where they react with the surface-adsorbed oxygen ions via the following reactions: ${ }^{10}$

$$
\begin{aligned}
& h_{\mathrm{vb}}^{+}+\mathrm{O}_{\text {ads }}^{-} \rightarrow \frac{1}{2} \mathrm{O}_{2 \mathrm{ads}}, \\
& \mathrm{O}_{2 \text { ads }} \rightarrow \mathrm{O}_{2 \text { gas }} .
\end{aligned}
$$

In the present investigation, the loss of surface-adsorbed oxygen ions is reflected in the gradual decrease in the original sensor resistance under UV exposure. The original sensor resistance stabilizes to a very low value of $1.5 \mathrm{M} \Omega$ with UV exposure. Correspondingly, a drastic reduction in the $\mathrm{H}_{2}$ sensitivity $(S=200)$ is also noted. Since an almost equivalent sensor resistance is attained in the presence of $900 \mathrm{ppm}$ of $\mathrm{H}_{2}$ under all conditions, the decrease in the original sensor resistance is primarily responsible for the reduced $\mathrm{H}_{2}$ sensitivity under UV exposure.

It is interesting to note that, similar to the results obtained in this investigation, in the literature, ${ }^{6}$ reduced carbon 
monoxide $(\mathrm{CO})$ sensitivity under UV exposure, relative to that without UV exposure, has been reported for pure- $\mathrm{SnO}_{2}$ thin-film sensor at $400{ }^{\circ} \mathrm{C}$. However, at room temperature, exactly opposite behavior has been observed for pure $\mathrm{SnO}_{2}$. The very low surface coverage of chemisorbed oxygen ions has been attributed to the negligible or no room-temperature $\mathrm{CO}$ sensitivity of pure- $\mathrm{SnO}_{2}$ thin-film sensor. ${ }^{6}$ The surface coverage of chemisorbed oxygen ions, however, increases at a higher operating temperature $\left(400{ }^{\circ} \mathrm{C}\right)$, at which UVdeactivated $\mathrm{CO}$ sensitivity is reported. In the present investigation, for the nanocrystalline $\mathrm{In}_{2} \mathrm{O}_{3}$-doped $\mathrm{SnO}_{2}$ thin-film sensor, reduced $\mathrm{H}_{2}$ sensitivity with $\mathrm{UV}$ exposure is noted at room temperature in contrast to $400{ }^{\circ} \mathrm{C}$, as reported for pure$\mathrm{SnO}_{2}$ thin-film sensor. This difference is due to the fact that the excess concentration of surface-adsorbed oxygen ions is achieved for the present sensor via doping $\operatorname{~In~}^{3+}$ cations and the small size of nanocrystallites $(<10 \mathrm{~nm})$, which was not possible using pure $\mathrm{SnO}_{2}$ thin-film sensor.

Lastly, it is necessary to mention that determining the effect of the different wavelengths of UV radiation (other than $375 \mathrm{~nm}$, which is utilized in this investigation) on the room-temperature sensor response is essential. Work in that direction is currently in progress.

\section{CONCLUSIONS}

Nanocrystalline $\mathrm{In}_{2} \mathrm{O}_{3}$-doped $\mathrm{SnO}_{2}$ thin-film $\mathrm{H}_{2}$ sensor is successfully sol-gel dip coated on the MEMS device. $\mathrm{H}_{2}$ gas at ppm level is successfully sensed at room temperature using the present sensor with and without exposure to UV radiation. A very high sensitivity, as high as $65000-110000$, is obtained at room temperature for $900 \mathrm{ppm}$ of $\mathrm{H}_{2}$ under the dynamic test condition. Exposure to UV radiation is observed to deteriorate the room-temperature $\mathrm{H}_{2}$ sensitivity $(S=200)$ of the present sensor. This loss in the $\mathrm{H}_{2}$ sensitivity is well explained based on the constitutive equation for the gas sensitivity of semiconductor oxide sensors and is attributed to the decrease in the original sensor resistance under UV exposure, which is a consequence of desorption of the surface-adsorbed oxygen ions. For a constant $\mathrm{H}_{2}$ sensitivity, the response time is minimum without UV exposure than that with UV exposure. The recovery time of 20-30 $\mathrm{min}$ is observed under both the conditions via the "nonconventional recovery" technique, which is successfully demonstrated. It is concluded that, at least for the present Pt-sputtered $\mathrm{In}_{2} \mathrm{O}_{3}$-doped $\mathrm{SnO}_{2}$ thin-film sensor incorporated into the MEMS device, sensing $\mathrm{H}_{2}$ at room temperature without UV exposure is the best sensing condition.

\section{ACKNOWLEDGMENTS}

The authors thank UCF, Florida Space Grant Consortium (FSGC), NASA-Glenn, KSC-NASA, and National Science Foundation (NSF EEC-0136710) for funding the sensor and the nanotechnology research. The authors also thank Dr. Tianbao Du, Keith Rea, and Sameer Deshpande (MMAE and AMPAC, UCF) for conducting AFM, FIB, and TEM analyses, respectively.

${ }^{1}$ S. R. Morrison, Sens. Actuators 2, 329 (1982).

${ }^{2}$ D. Kohl, Sens. Actuators 18, 71 (1989).

${ }^{3}$ S. Seal and S. Shukla, JOM 54, 35 (2002).

${ }^{4}$ N. Yamazoe, Sens. Actuators B 5, 7 (1991).

${ }^{5}$ J. Saura, Sens. Actuators B 17, 211 (1994).

${ }^{6}$ P. Camagni, G. Faglia, P. Galinetto, C. Perego, G. Samoggia, and G. Sberveglieri, Sens. Actuators B 31, 99 (1996).

${ }^{7}$ E. Comini, A. Cristalli, G. Faglia, and G. Sberveglieri, Sens. Actuators B 65, 260 (2000).

${ }^{8}$ E. Comini, G. Faglia, and G. Sberveglieri, Sens. Actuators B 78, 73 (2001).

${ }^{9}$ M. Bender et al., Thin Solid Films 418, 45 (2002).

${ }^{10}$ E. Comini, L. Ottinin, G. Faglia, and G. Sberveglieri, IEEE Sens. J. 4, 17 (2004).

${ }^{11}$ G. K. Mor, M. A. Carvalho, O. K. Varghese, M. V. Pishko, and C. A. Grimes, J. Mater. Res. 19, 628 (2004).

${ }^{12}$ S. Shukla, S. Patil, S. C. Kuiry, Z. Rahman, T. Du, L. Ludwig, and S. Seal, Sens. Actuators B 76, 343 (2003).

${ }^{13}$ S. Shukla, S. Seal, L. Ludwig, and C. Parish, Sens. Actuators B 97, 256 (2004).

${ }^{14}$ S. Shukla, L. Ludwig, and C. Parish, Sens. Actuators B 104, 223 (2004).

${ }^{15}$ T. L. Barr and S. Seal, J. Vac. Sci. Technol. A 13, 1239 (1995).

${ }^{16}$ B. I. Prenitzer, L. A. Giannuzzi, K. Newman, S. R. Brown, R. B. Irwin, T. L. Shoftner, and F. A. Stevie, Metall. Mater. Trans. A 29, 2399 (1998).

${ }^{17}$ J. F. Moulder, W. F. Stickle, P. E. Sobol, and K. D. Bomben, in Handbook of X-Ray Photoelectron Spectroscopy: A Reference Book of Standard Spectra for Identification and Interpretation of XPS Data, edited by J. Chastain (Perkin-Elmer Corporation, Physical Electronics Division, Minnesota).

${ }^{18}$ S. Shukla and S. Seal, Sensor Letts. 2, 73 (2004).

${ }^{19}$ S. Shukla and S. Seal, Sensor Letts. 2, 125 (2004).

${ }^{20}$ S. Shukla and S. Seal, Sensor Letts. 2, 260 (2004).

${ }^{21}$ H. Ogawa, M. Nishikawa, and A. Abe, J. Appl. Phys. 53, 4448 (1982).

${ }^{22}$ S. Shukla and S. Seal, J. Nanosci. Nanotechnol. 4, 141 (2004). 